\title{
Energy Efficiency Dashboard for Small Businesses in the Illawarra
}

\author{
M. Safadi ${ }^{\mathrm{a}^{*}}$ \\ J. $\mathrm{Ma}^{\mathrm{a}}$ \\ R. Wickramasuriya ${ }^{a}$ \\ V. Somashekar ${ }^{\mathrm{a}}$ \\ O. El Fakih ${ }^{\mathrm{b}}$ \\ L. Yalan ${ }^{b}$
}

\begin{abstract}
Energy consumption by small and medium enterprises (SMEs) is increasingly becoming a matter of profitability for many businesses and a source of concern for Government agencies. Recognizing the need to improve SME's energy consumption, the NSW - Office of Environment and Heritage (NSW-OEH) has successfully implemented a business-focused energy efficiency program. The program involved individual audits conducted by certified assessors, estimating actual energy use by appliances and providing recommendations for retrofitting of more energy efficient equipment. The SMART Infrastructure Facility and the NSW$\mathrm{OEH}$ have partnered to create an online and interactive data portal (the Energy Efficiency Dashboard - EED) that brings together information collected throughout the energy efficiency program in order to better inform other business managers about the opportunities to improve their profitability and sustainability. This paper demonstrates how the Energy Efficiency Dashboard, a fusion between Business Intelligence and Geographic Information Systems, can provide a robust, highly interactive, online analytical dashboard to evaluate the effectiveness of the energy savings program. Uses of the EED include identification of business-specific best energy saving appliances and practices, business types with high potential for saving energy, and benchmarking energy use across business types.
\end{abstract}

Key words: Dashboard; Energy efficiency; SME.

\section{Introduction}

Small and medium enterprises (SMEs) shape a significant and important part of the Australian economy. In 2011, there were approximately 1.96 million actively trading small businesses in Australia comprising $96 \%$ of the total businesses. SMEs account for over a third of the total

\footnotetext{
${ }^{\text {a }}$ SMART Infrastructure Facility, University of Wollongong, Wollongong, NSW 2522, Australia

${ }^{\mathrm{b}}$ NSW - Office of Environment and Heritage, Level 2, 1 Fitzwilliam Street, Parramatta, NSW 2150, Australia

*Corresponding author: Murad Safadi murad@uow.edu.au

http://dx.doi.org/10.14453/isngi2013.proc.41
} 
production, and employ around $50 \%$ of the private non-financial sector, $33 \%$ of these businesses are located in $\mathrm{NSW}^{1-2}$.

The Australian Industry Group (Ai Group) conducted a survey on energy efficiency of businesses throughout April and May 2012, which targeted all sectors and states with a total of 319 respondents $^{3}$. Results showed that the amount businesses spent on energy increased between 2008 and 2011 which negatively affected businesses' profitability. Further, the survey indicated that NSW and SA businesses have been affected the most. As a result, NSW and SA businesses were more proactive than other states to take steps to improve their energy efficiency to reduce energy costs. Reducing business expenditure is one of the main motivations for businesses to take energy efficiency actions. The most common action taken was to change the staff practices towards energy consumption ${ }^{3}$.

The importance of energy efficiency improvement has been a significant issue since the early $1970 \mathrm{~s}^{4-5}$. The driving forces behind these programs include economic, social and environmental factors ${ }^{4}$. Communicating and educating the energy efficiency benefits to business users and decision makers is a critical part in ensuring SME community involvement in implementing government policies. The International Energy Agency (IEA) Scoreboard report for 2011 identified that some areas still require further development. Such areas are the availability of benchmarking information, incentives to make investment decisions and the need to design, improve and measure policies with specific focus on SMEs ${ }^{6}$.

SMEs invest substantial resources into the daily operation of their businesses ${ }^{7}$. Typically, SMEs lack the time and resources to invest in an energy efficiency project. Most SMEs consider such projects only when it can provide quick win and short payback period ${ }^{8}$. Many countries, including Australia, created energy saving policies and promoted energy efficiency programmers for SMEs. The challenge to policy makers is to reduce the information gap with minimum cost to $\mathrm{SME}^{9}$.

The NSW - Office of Environment and Heritage (NSW-OEH) has successfully implemented a business-focused energy efficiency program. This program helps SMEs reduce their energy costs and overcome many non-price barriers such as lack of capital and time. Those who invest in this program can cut energy cost without sacrificing service or quality, make significant contributions to a cleaner environment and improve their financial bottom line ${ }^{9}$. From state government's point of view, EED is an analytical web portal that enables assessing the effectiveness of OEH's energy efficiency program.

\section{The Energy Efficiency Dashboard}

The SMART Infrastructure Facility at the University of Wollongong and the NSW-OEH have partnered to create an online analytical and reporting portal. This portal brings together information collected throughout the energy efficiency program in order to better inform business managers about the opportunities to improve their profitability and sustainability. The data portal (EED), shown in Figure 1, is designed to help SME overcome the information barrier and provide benchmarking information by presenting an effective, robust and highly interactive online analytical tool. 


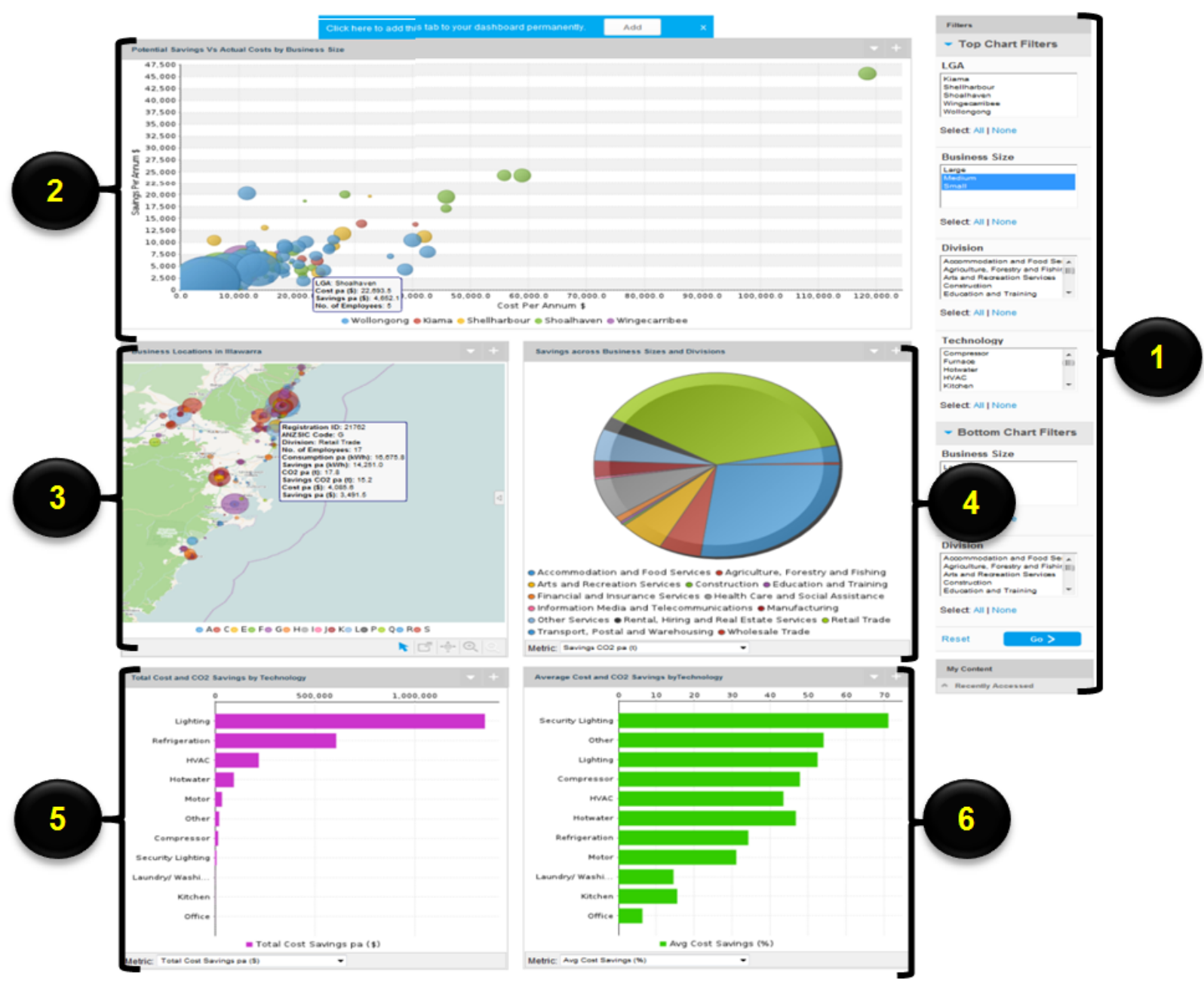

Figure 1: The Energy Efficiency Dashboard (EED)

To reduce the information gap, EED provides SME managers and decision makers in the Illawarra a benchmarking tool to understand how their business compare with other businesses from the same industry. EED focuses on presenting appropriate energy consumption and potential saving for SME in the Illawarra in a user-friendly fashion based on the user's defined role. EED turns the energy consumption data into knowledge that is easy to share with decision makers, policy makers and SME managers.

The dashboard includes identification of business-specific best energy saving appliances and practices, business types with high potential for saving energy and benchmarking energy use across business types. As a result, business users can evaluate and compare the effectiveness of their energy savings practices with other businesses in the same industry. 


\section{Study Area}

The study area corresponds to the Illawarra region (NSW, Australia). This coastal region, located south of Sydney, is made of five Local Government Areas (LGAs): Wollongong, Shellharbour, Kiama, Shoalhaven, and Wingecarribee.

\section{Data sets}

The data sets covered 1027 businesses with the majority located in the Wollongong area with $594(57.8 \%)$ businesses followed by Shoalhaven 192 (18.7\%), Shellharbour 121 (11.8\%), Wingecarribee $74(7.2 \%)$ and Kiama $46(4.5 \%)$.

\section{User Interface Design}

The EED is divided into the following six areas:

1) Filters: allow user to choose constraints that are relevant for their assessment, including LGA, Business Size (S/M/L), Technology and Division (according to the Australian and New Zealand Standard Industrial Classification - ANZSIC). Users can select one, more than one or all of these selections. It allow users to control all reports at once

2) Potential Savings Vs Actual Costs by Business Size: is a statistical bubble chart that shows the relationship between business electricity cost per annum and the potential savings. The color of a bubble indicates the LGA area whereas its size indicates the size of business based on the number of employees. Therefore, this bubble chart is an ideal tool to investigate the relationship of utility consumption and potential energy savings based on business size, location and industry.

3) Business location in the Illawarra: provides added value to users wishing to identify a business division and its potential saving. A SME manager is able to see all businesses clustered in the Illawarra region with individual total energy consumption and potential savings. From there s/he can drill into the equipments energy consumptions and its potentials savings level (see figure 2). 
International Symposium for Next Generation Infrastructure October 1-4, 2013, Wollongong, Australia

Table - Chart Representaion for Selected Business

OEH, 1/11/2012 11:47 AM

\begin{tabular}{|c|c|c|c|}
\hline Technology & Savinge pa (kWh) & Savings pa (\$) & CO2 Savinga pa (t) \\
\hline Refrigeration & $9,863.8$ & $2,501.4$ & 10.6 Retall Trade \\
\hline Lighting & $5,948.9$ & $1,508.7$ & 6.4 Retall Trade \\
\hline Hotwater & 838.8 & 212.8 & 0.9 Retall Trade \\
\hline
\end{tabular}

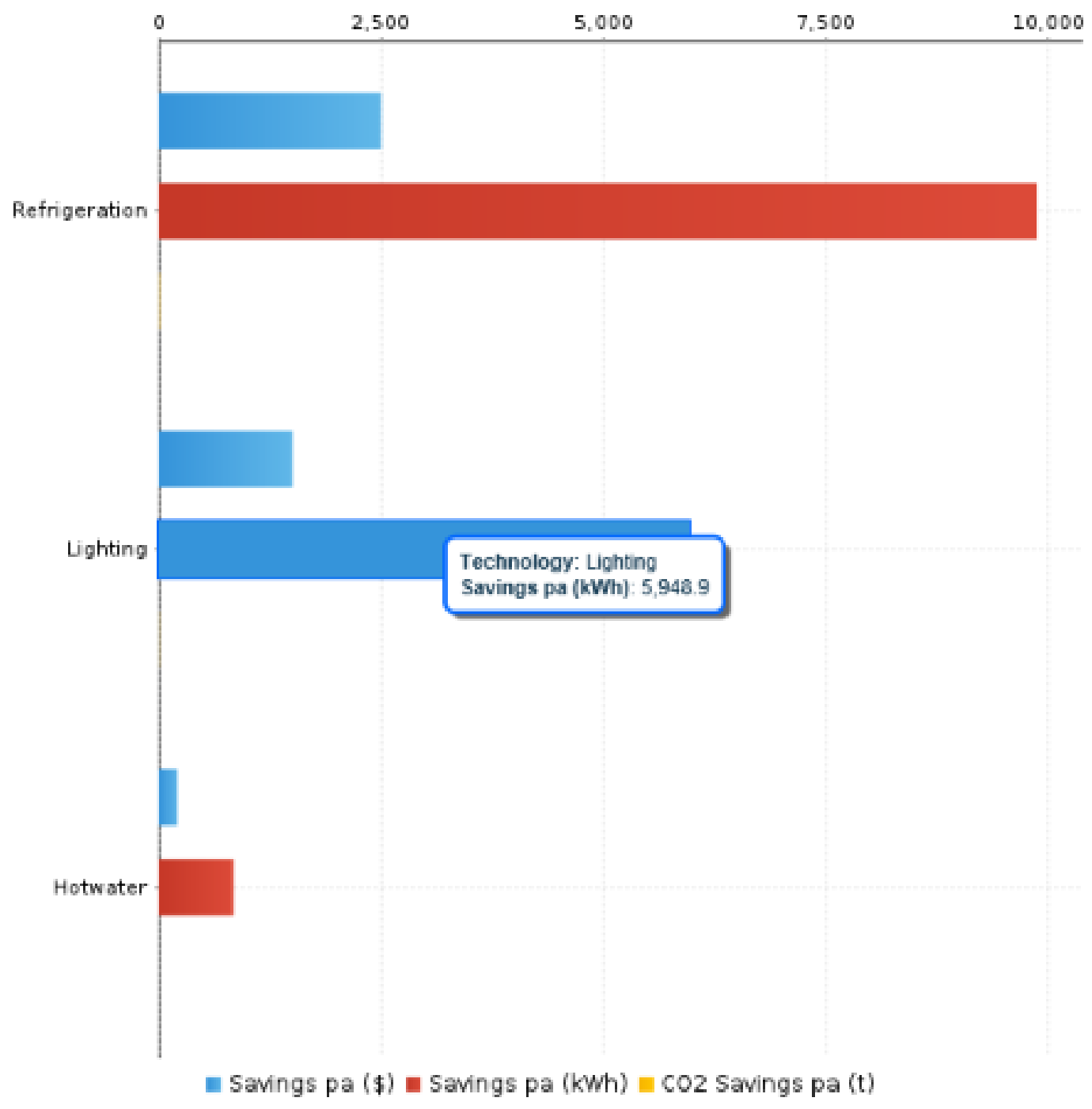

Figure 2: Equipment's potential energy saving 
4) Savings across Business Size and Divisions: through this pie chart users can find the level of potential savings for each ANZSIC's division. This report also drills through to an integrated child report that enables "what-if" scenario analysis (see Figure 3). Using this integrated report, a user can estimate the expected utility consumption for a given industry under various scenarios, and compare the predicted value with the base case both in tabular form. For example, using a certain value for the population increase the user can see what efficiency gains would keep the expected usage within manageable limits. The usability and flexibility of this report is that it presents the user with a few easy-to-use sliders and filters to perform multiple scenario analyses on uptake of energy efficiency programme by SMEs.

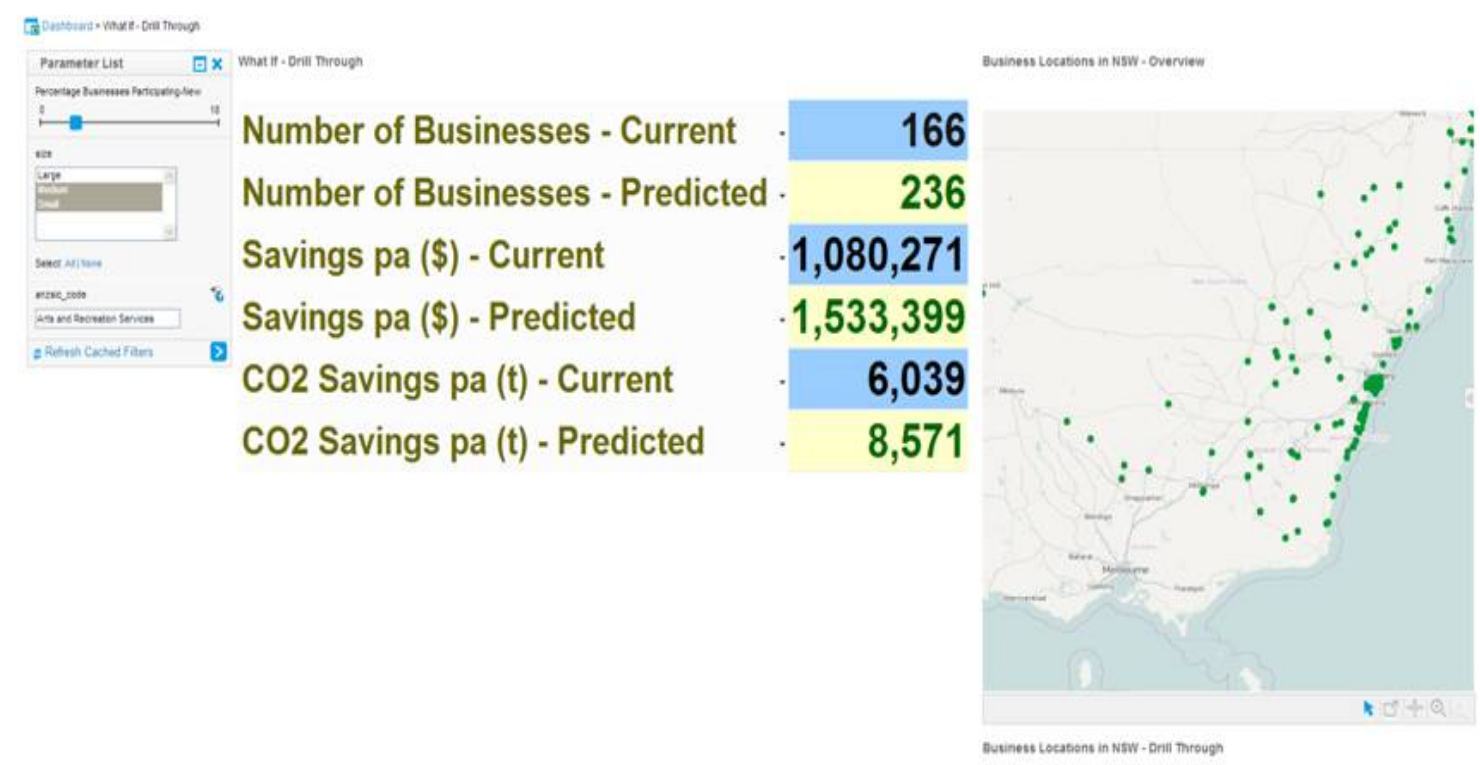

Figure 3: What-If Scenario Analysis

5) Total cost and CO2 Savings by Technology: a bar graph that provides an overall view of potential savings pa in dollar value and tonne. The savings are presented in ascending order by equipment type such as HVAC, Refrigeration and Lighting.

6) Average Cost and $\mathrm{CO} 2$ Savings by Technology: this bar graph that provides an overall view of potential savings pa in dollar value and tonne. The savings are presented in an ascending order by equipment type. 


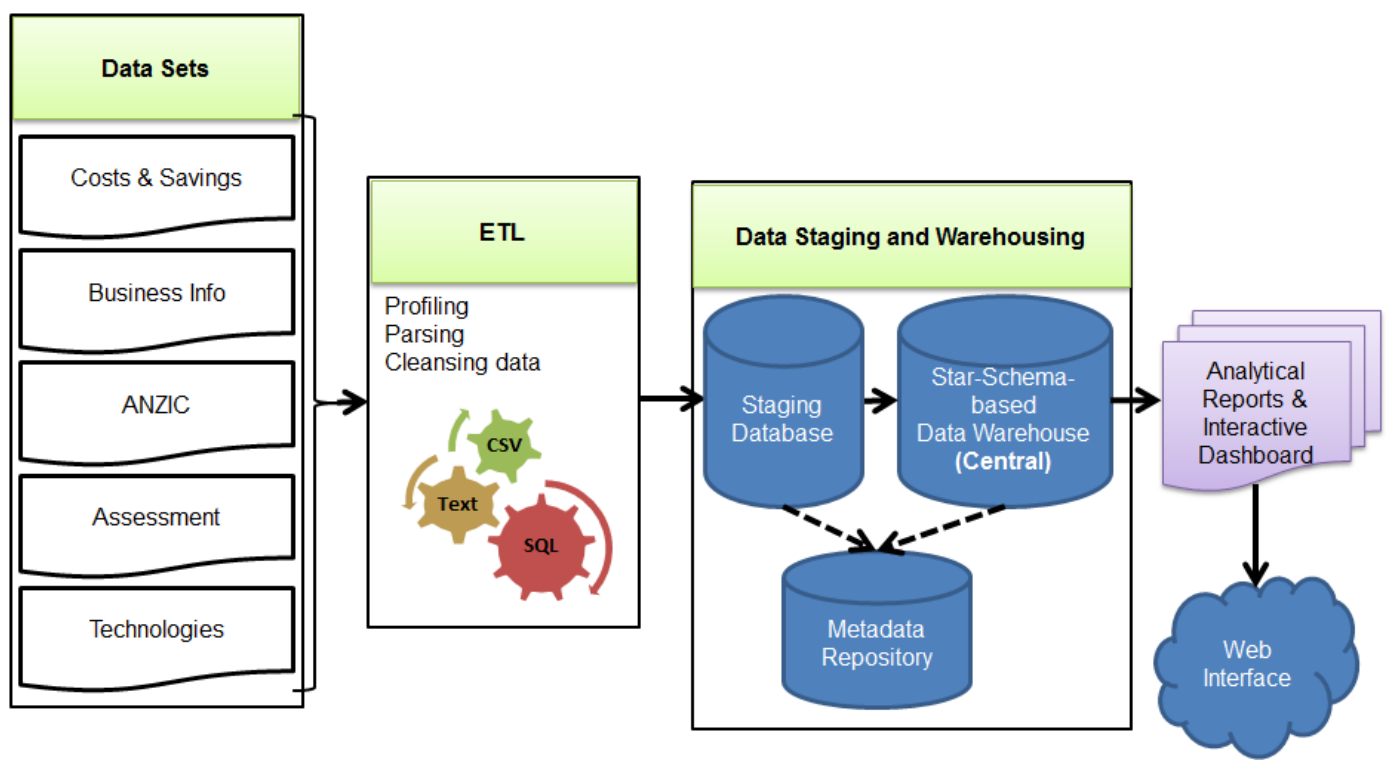

Figure 4: Technical Architecture and Workflows

\section{Technical Architecture and Workflows}

We first describe the technical architecture and workflows involved in building the EED, and then how the users and policy makers could use this collection of tools. Figure 4 gives an overview of EDD and main workflows involved.

\section{ETL}

EED receives data from a number of providers in assorted file types and in heterogeneous structures. Extract, Transform and Load (ETL) is the standard process implemented to migrate such diverse data into an optimized data warehouse environment. This is applied in two stages process. In the first stage, data from disparate sources are extracted into a staging database where data cleaning, profiling and transforming operations take place. In the second stage, transformed data are loaded into a centralised star schema-based data warehouse.

\section{Star Schema}

The data warehouse is based on a Star Schema design. It maps data into one or more fact tables with multidimensional tables. A star schema can simplify data structure and provide capability to analyse data from multiple dimensions, thus enabling a user to perform various drill down, roll up and slice-and-dice views of data [8]. Coronel et al. (2013) provide an in-depth description of star schema and its variations used in data warehousing.

\section{Analytical Reports \& Interactive Dashboard}

Reports \& Dashboard use Web-based technologies to present energy efficiency information in a single view. These reports are built on top of the optimised star schema-based data warehouse. 
End users access this interactive content via an online portal with multiusers and multilevel access control. These access controls provide customised views of the data for different users.

\section{Conclusion}

The importance of energy efficiency improvement for SMEs has been a significant issue for several decades. Yet, there has been little action among SMEs to adapt their operations to enhance energy efficiency. NSW-OEH has successfully implemented a business-focused energy efficiency program, the purpose of which is to provide access to benchmarking information about the program and reduce the information gap. This program has the potential to highlight the opportunities available to SME managers to increase the energy efficiency of their businesses. EED is designed to provide such information for SME in the Illawarra.

The goals of EED go beyond providing energy efficiency and consumption related information for SMEs in the Illawarra; the portal targets stakeholders to communicate more effectively and provide benchmarking levels based on business categories. It is an easily scalable and flexible technology that can include an unlimited number of LGAs.

\section{References}

${ }^{1}$ Department of Industry, Innovation, Science, Research and Tertiary Education, Australian small business. Key statistics and analysis, 2011. Retrieved from http://www.innovation.gov.au.

${ }^{2}$ Connolly, E., Norman, D., and West, T., Small Business: An economic review. Small Business Finance, Roundtable 2, 2012. Retrieved from http://www.abs.gov.au.

${ }^{3}$ Gomez, K., Ai, Group highlights mounting pressure on businesses from rising energy prices. PACE, 2012, July 16. Retrieved from http://www.pacetoday.com.au.

${ }^{4}$ Armstrong, G., "Issues in energy efficiency," National Economic Review, Vol. 64, 2010, pp. 46-54.

${ }^{5}$ Gellar, H., Harrington, P., Rosenfeld, A.H., Tanishima, S., and Unander, F., "Policies for increasing energy efficiency: Thirty years of experience in OECD countries," Energy Policy, Vol. 34, 2006, pp. 556-573. http://dx.doi.org/10.1016/j.enpol.2005.11.010

${ }^{6}$ International Energy Agency. IEA Scoreboard 2011: Implementing energy efficiency policy: Progress and challenges in IEA Member Countries. Washington, DC: OECD Publishing, 2011.

${ }^{7}$ NSW Business Chamber. Energy efficiency. Submission to the Prime Minister's task group, 2010. Retrieved from http://nswbusinesschamber.com.au.

${ }^{8}$ Coronel, C., Morris, S., and Rob, P., Database systems. Design, Implementation, and management, Cengage Learning: Boston, 2013.

${ }^{9}$ ACIL Tasman Pty Ltd. Energy efficiency opportunities program review, 2013. Online: http://eeo.govspace.gov.au. 